\title{
Using Data To Enhance Decision Making: Graduation Initiative 2025
}

\author{
Shari McMahan, California State University, San Bernardino, USA \\ Muriel C. Lopez-Wagner, California State University, San Bernardino, USA
}

\begin{abstract}
The California State University launched its Graduation Initiative 2025 in January 2015 with a clear goal to increase graduation rates for our 475,000 students across all 23 campuses. The Graduation Initiative 2025 will add 100,000 more baccalaureate degree-educated citizens to California over the next ten years and begin to meet workforce demands. Increasing graduation rates, particularly for first-generation students, requires a strategic, data-driven approach. California State University, San Bernardino (CSUSB) faces particular challenges as $81 \%$ of our undergraduate population are first-generation college students, 63\% receive Pell Grant, and 56\% of incoming firstyear students require some form of developmental coursework in English, math, or both. Data-driven decision-making must be used to focus graduation efforts. CSUSB organizes data regarding college readiness, and enrollment characteristics as preparedness have a direct influence on time to degree. Data on persistence and progress towards the degree are also important to track when examining graduation rates as it helps identify areas to improve. Finally, data on completion and post-graduation are indicators to track the progress of the initiative and meeting workforce demands.
\end{abstract}

Keywords: College Graduation; Graduation Rate; Data-Driven Decision-Making; California Workforce

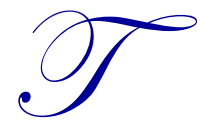

he California State University (CSU) launched the Graduation Initiative 2025 (GI2025) with a clear objective to increase graduation rates for 475,000 students across 23 campuses. The goal is to meet the 1.1 million predicted shortage of college graduates in California by 2030 (Johnson, Mejia, \& Bohn, 2015). That translates to adding more than 100,000 baccalaureate prepared citizens each year over the next 13 years.

Pressures to increase graduation rates by federal and state decision-makers have required academic leaders to pay close attention to graduation rates and prioritize efforts to decrease time to degree. CSU has an overall four-year graduation rate goal of $57 \%$ by 2025 while the current rate is $19 \%$, an anticipated increase of $38 \%$ in the next eight years (Blanchard, 2016). The goal is optimistically above the latest public, four-year graduation rate of $34 \%$ (Chronicle Higher Education College Completion, 2017).

California State University, San Bernardino (CSUSB) is located in the Inland Empire in Southern California and comprises both San Bernardino and Riverside counties. The Inland Empire has a total population of over 4 million with a median income of approximately $\$ 56,000,9 \%$ below California's median family income of $\$ 63,783$ (U.S. Census Bureau). Thirty-two percent of California has at least a bachelor's degree while Riverside $(21 \%)$ and San Bernardino (19\%) has less (U.S. Census Bureau). At CSUSB, $81 \%$ of our undergraduate population are firstgeneration college students, $63 \%$ receive Pell Grant, and 56\% of incoming first-year students require some form of developmental coursework in English, math, or both (CSUSB, Office of Institutional Research, 2017). Several years ago, only $9 \%$ of students completed their bachelor's degree in four years which has increased to $14 \%$ in recent years (CSUSB, Office of Institutional Research, 2017). CSUSB's goal by 2025 is to reach the $30 \%$ mark while eliminating the achievement gap for Pell recipients, underrepresented minority, and first-generation students.

Reducing time to degree requires an all hands on deck approach. A cross-divisional commitment and action are necessary to examine the efficacy of programs and interventions, question what works and what does not, identify key data needed, and monitor students' progress towards their degree. It is common to get multiple and different answers from different sources on campus when asking for data. When a campus designates one place as the reliable source 
of a data repository, such as institutional research, institutional effectiveness, or the like, this is a practice of institutional intelligence.

One element indicative of institutional intelligence is the use of data analytics accessible by any member of the campus community whether data are presented at the institutional level or the departmental level. Other critical elements of institutional intelligence include the availability and accessibility of information, insights shared to campus by leadership, faculty, student affairs folks, and other staff, and a coordinated campus approach on transforming data analytics from hindsight to insight and further to foresight (Norris \& Baer, 2013).

To understand the practices of institutional intelligence, one should be prepared to ask the right questions from the beginning. For instance, when looking at six-year graduation rates using IPEDS (U.S. Department of Education, National Center for Education Statistics, Integrated Postsecondary Education Data System), it would be important to know that IPEDS present data at the cohort level at full-time status and graduation in the same institution. The National Student Clearinghouse, for instance, includes graduation at another institution as part of the graduation rate. WASC Senior College and University Commission (WSCUC) presents graduation rate based on units redeemed for a degree and takes into consideration those attending on a part-time basis. In some academic departments, graduation rate is defined as the start and completion of a degree within the same major, or completion of a degree in any department or college. Thus, it is important to know which questions to ask and understand how data are captured (Rorison \& Voight, 2015).

The important piece of institutional intelligence is understanding the context you have shaped for your students. When students embark on their career journey, a host of milestones must occur between high school and college leading to career placement (Institute for Higher Education Policy, 2014). Each step through the pipeline is intentional as well as the institutional context and resources that support the student where data, decisions, and collective action intersect are keys to building the optimum ecosystem for the students.

\section{COLLEGE READINESS}

The first part of the ecosystem is students' college readiness, that is, preparedness for English and math in the case of CSUSB. At fall 2016, 68\% of CSUSB first-year students required some form of developmental coursework in math and English at admission as evaluated by the Entry Level Mathematics Test (ELM) and English Placement Test (EPT) placement tests required by the CSU. Depending on students' scores in these tests, students are asked to do "early start" coursework before arriving in the fall to prepare them for college math and English by the fall quarter. It is possible that students' first year at CSUSB could include up to five developmental coursework in math and English that do not count towards their degree. If they are not college ready at admission, could not complete the early start summer program, and have to spend their first year in college doing developmental coursework, then students time to graduation could be longer than four years. Moreover, additional co-occurring factors interact with college readiness such as socioeconomic variables (e.g., Conley, 2008; Roderick, Nagaoka, \& Coca, 2009). At the same time, data also suggest that students, regardless of characteristics, who are ready for college math in the fall term are more likely to graduate in a timely fashion than students requiring developmental coursework in college. At this time, the CSU Graduation Initiative is changing these requirements. Placement tests in math and English will no longer be required beginning in 2018. Rather, the CSU will consider multiple measures of math and English performance during and immediately after high school. The elimination of placement tests is an instance where students' context is altered considerably and favorably to promote graduation within four years.

\section{ENROLLMENT}

Due to increasing number of student applications and decreasing amount of funding from the state, the CSU has mandated that campuses serve in large part their surrounding/local area. A dialogue should occur between superintendents of school districts and the enrollment management officials of the university to monitor enrollment. Discussions should include strengths and weaknesses in academic areas of students within a school district, achievement gaps that emerge before college admission, application at the university to an impacted major, grade point average, and other factors. These discussions could change college preparation activities at the school district level, policies, curriculum, and could provide a robust context for intervention when students arrive at the university. 
Additionally, students transferring from the community colleges should transfer in with the Associates Degree of Transfer (ADT), to help further streamline graduation timelines.

\section{PERSISTENCE}

Once students matriculate at a college or university, it is important for campus leaders to monitor persistence factors such as levels of student engagement, retention rates (into the second year, third year, and so on), and the provision of quality student support services. These services encompass many programs and services who have direct contact with students such as advising, financial aid, clubs, and organizations. Equally important is the continuous improvement process of these services to adjust and innovate according to changing times and needs. The role of persistence in students' lives is a potentially powerful one because persistence could change outcomes. Persistence could mediate or moderate the influence between precollege characteristics and outcomes such as graduation, and is highly malleable to intervention (e.g., Kuh, Kinzie, Buckley, Bridges, \& Hayek, 2006; Martinez, Sher, Krull, \& Wood, 2009). Therefore, any student services office should be able to evaluate the quality of their services, be able to continuously improve these services, and be able to embed intentionality in the decision-making process because these changes affect students' lives and outcomes.

\section{PROGRESS}

Technological infrastructure has an important role in creating a context for campus leaders to track students' progress towards graduation. For example, data analytics could provide information on the distinction between units towards a degree versus overall units accumulated. There are many instances where students may have well over 180 quarter units (120 semester units) and be nowhere near degree completion. Technology can track bottleneck courses that hinder a student's ability to progress promptly. Understanding various definitions of bottleneck courses (e.g., high failure rate, high repeat rate, an insufficient number of sections, courses offered once a year) is important to show in data analytics to adequately plan course offerings and additional faculty in subsequent years. Technology also has an important role in providing solutions for students such as a dashboard that assists them in finding open seats in classes or for an advisor being able to identify students taking courses repeatedly. Technological infrastructure, data analytics, and decision-makers can shape policies and deploy services to students that can alleviate impediments to graduation. It is the coordinated efforts of people and technology that develop a context for success.

\section{COMPLETION}

As students approach graduation, it is important that campus leaders know the number of transcripts reviewed for graduation, students missing classes or units required for graduation, filing for graduation, and participation in commencement exercises. It is critical to catch students early enough to offer particular classes so they can graduate when they plan to. Students should be able to access critical services such as career or graduate school advising. The coordinated efforts between the registrar, advisors, and department chairs could provide a healthy ecosystem for students and provide a robust beginning for workforce development or graduate education.

\section{POST-GRADUATION}

The students' ecosystem continues as the goals of GI2025 lead to workforce development and we can assess the skills, knowledge and competency to be successful. It is important, albeit challenging, to capture alumni data immediately after graduation and years later. To better understand the market demand for particular majors, university leaders should continue to work with local, regional economic development, employment development agencies, and the industry to best gauge employment and workforce engagement that could inform career centers on campuses, and perhaps even spark discussions about specific majors.

An optimal ecosystem for students is one where people and offices collaborate and work towards the same outcomes for students. Collaboration entails institutional intelligence and action. Benefits to students are enormous when campuses go through a careful, intentional process to increase timely graduation in the case of the Graduation Initiative. This process increases accountability among unit heads and deans to move responsibly and focus on common goals. It encourages objectivity when examining potentially sensitive information such as high failure rate 
courses and highlights areas of weaknesses and gaps in practices. It can be a critical tool in improving access and diversity and can improve student, faculty, and staff success (Messelt, 2004).

\section{EFFECTIVE PROGRAMS AT CSUSB}

Starting with the fall 2008 and fall 2009 cohort of students, CSUSB implemented a pilot program and served approximately 1,800 in each cohort of 2,000 first year students to receive a coordinated package of services during the summer. The Student Orientation, Advising and Registration (SOAR) program was a tightly planned schedule of student orientation, advising, registration, financial aid, and peer mentorship which included an overnight stay on campus in the residence halls. The program was designed to promote feelings of belongingness to campus and teach students how to register for classes. According to research conducted by CSUSB Office of Institutional Research (Rose, 2014), results showed that those who attended SOAR had a higher first term GPA, attempted and completed more units in general, and attempted and completed more units in general education compared to those who did not attend SOAR. SOAR participants were also retained and graduated within four years at a higher rate than those who did not participate in SOAR. Moreover, staying overnight on campus appeared to be important. SOAR overnighters had a higher first term GPA, higher retention rate, and higher scores in college involvement and social agency scales than SOAR non-overnighters. These promising findings led CSUSB to make SOAR mandatory to all new students starting with the fall 2010 cohort and eventually became part of the first year experience that today includes a new student convocation where families spend the day on campus.

Supplemental Instruction (SI) was implemented at CSUSB in 2012 based on the model from University of Missouri, Kansas City. SI was designed to provide a robust academic support for students who take historically difficult courses, to increase retention, and increase grades in those difficult courses. At that time, SI provided support for four courses serving about 50 students. Results showed that fall 2013 first year students who participated in SI had significantly higher grades in those classes and were more likely to pass than students who did not participate in SI although no significant differences were found in their academic self-confidence and involvement in college life (CSUSB Office of Institutional Research, 2014). Today, SI supports 22 to 25 courses (40 to 44 sections) across 11 academic departments and serving over 4,500 students. Recent results using matched samples indicated similar findings in which SI participants received higher grades than non-SI participants (CSUSB Office of Institutional Research, 2017).

CSUSB had the Intensive Math Program (IMP) from 2002 to 2014 to meet the needs of incoming first year students who required developmental math. Designed by math faculty, this program was taught for five weeks each summer for seven hours per day and with intensive support from tutors. IMP served between 100 and 200 students each summer. Findings suggested no significant difference in college math grades between IMP students and their college ready peers (Vanderburgh, et al. 2015). Moreover, a higher number of IMP students were more likely to complete their college math requirement during the first year and were more likely to be retained than their college ready peers. In summer 2015, the IMP program was scaled up to become Coyote First STEP (CFS) which began to serve 1,000 to 2,000 of the incoming students who required developmental math. In addition to the math program, CFS deployed other services to students such as informational literacy skills training, financial literacy, study skills, degree planning, and service learning while they lived on campus housing between two weeks and one month. CFS was free to students. Recent results show that $91 \%$ of incoming first year students who required developmental math at admission reduced the number of developmental math course by at least one level (Kanatsu, et al. 2017). Fifty-nine percent of CFS participants became ready for college math by the fall quarter.

\section{GRADUATION RATE}

Consistent improvements on the four-year graduation rate over a period would indicate strong evidence of a wellcoordinated campus approach to the Graduation Initiative. However, most massive program implementation at CSUSB occurred after the fall 2013 cohort such as CFS, course redesign, and intrusive advising which means data will not be available until years later. In the meantime, an increase has emerged for the fall 2013 cohort. CSUSB anticipates reaching the goal of $30 \%$ by 2025 for the fall 2021 cohort with diminished equity gaps for Pell recipients, underrepresented minority, and first-generation students. Finding consistency in programmatic improvements is the biggest challenge for our campus. 
Figure 1. CSUSB Four-Year Graduation Rate of Full-Time, First Year Students

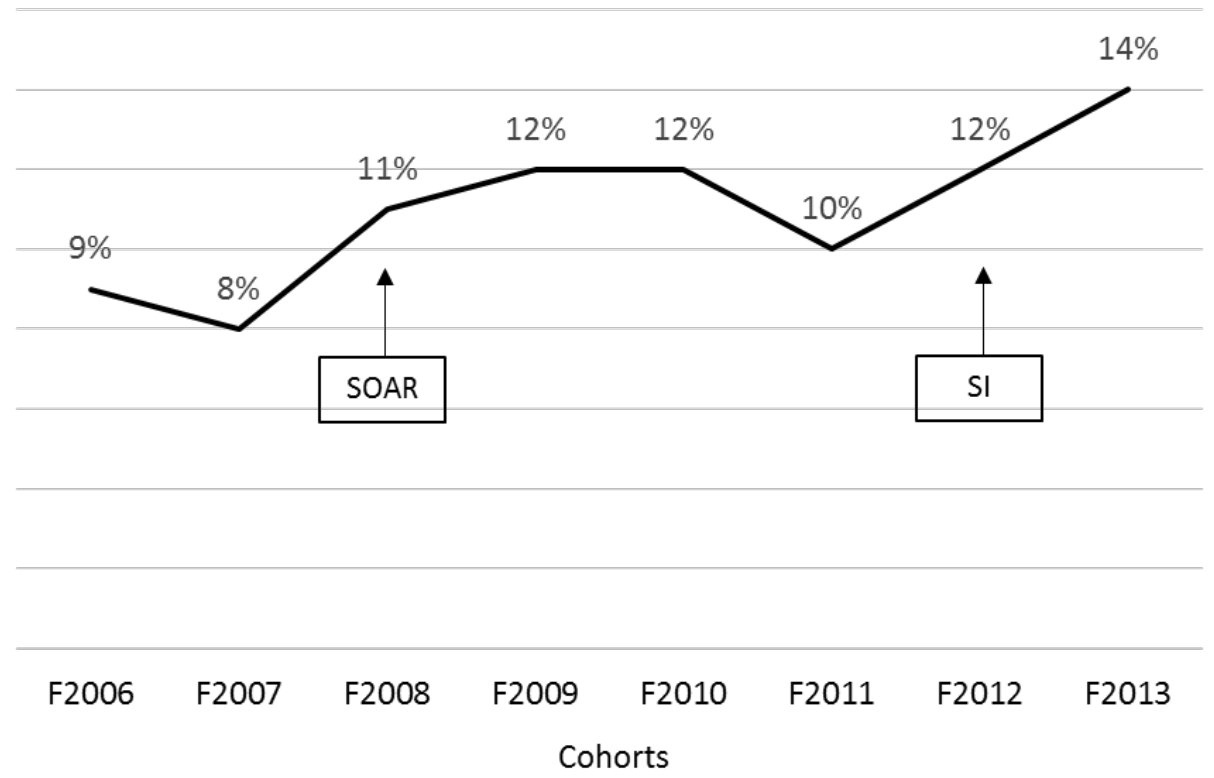

\section{AUTHOR BIOGRAPHIES}

Shari McMahan serves as Provost of Cal State San Bernardino (CSUSB). The student population is over 20,000 with most (86\%) of the students coming from San Bernardino and Riverside Counties. First-to-second year retention rate is fourth highest among all 23 CSU campuses. CSUSB reflects the dynamic diversity of the region and has the most diverse student population of any university in the Inland Empire, and it has the third highest African American and Hispanic enrollments of all public universities in California. Dr. McMahan co-leads the Graduation Initiative 2025 efforts on the campus.

Muriel C. Lopez-Wagner is the Assistant Vice-President of Institutional Effectiveness and Director of Institutional Research at California State University, San Bernardino. She has 17 years of experience in the field of institutional research. She leads campus efforts on institutional intelligence especially in areas of dashboard analytics, student success initiatives, and enrollment planning for the purpose of decision-making and continuous improvement.

\section{REFERENCES}

Blanchard, L. J. (2016). Call for campus student success plans pursuant to AB 1602. CSU Chancellor's Office memo, July 29, 2016.

Johnson, H., Mejia, M. C., \& Bohn, S. (2015). Will California run out of college graduates. San Francisco: Public Policy Institute of California.

Chronicle Higher Education (2017). College completion. Retrieved from http://collegecompletion.chronicle.com/state/\#state=ca\&sector=public_four.

Conley, D. T. (2008). Rethinking college readiness. New Directions for Higher Education, 144, 3-13.

CSUSB, Office of Institutional Research (2014). Did you know freshmen who participated in Fall 2013 supplemental instruction achieved a higher course grade, May 2014.

CSUSB, Office of Institutional Research (2017). Did you know students who attended supplemental instruction received higher grades, February 2017.

CSUSB, Office of Institutional Research (2017.) Retrieved from https://www.csusb.edu/institutional-research. Institute for Higher Education Policy (2014). Driving toward greater postsecondary attainment using data. Washington, DC. 
Kanatsu, A., Satterlund, A. M., Aragon, B., Study, D., Oxendine, J., Quinonez, L., Lopez-Wagner, M. C., ...\& Rizzo, T. (2017). Coyote first STEP 2016 Report \#2. San Bernardino: California State University, San Bernardino, Office of Institutional Research.

Kuh, G. D., Kinzie, J., Buckley, J. A., Bridges, B. K., \& Hayek, J. C., (2006). What matters to student success: A review of the literature. Commissioned Report for the National Symposium on Postsecondary Student Success: Spearheading a Dialog on Student Success. National Postsecondary Education Cooperative. Washington, DC: U.S. Department of Education.

Martinez, J. A., Sher, K. J., Krull, J. L., \& Wood, P. K. (2009). Blue-collar scholars? Mediators and moderators of university attrition in first-generation college students. Journal of College Student Development, 50(1), 87-103.

Messelt, J. (2004). Data-driven decision making: A powerful tool for school improvement. A white paper. Sagebrush Corporation.

Norris, D. \& Baer, L. (2013). Building organizational capacity for analytics. Educause Publications.

Roderick, M., Nagaoka, J., \& Coca, V. (2009). College readiness for all: The challenge for urban high schools. The Future of Children, 19(1), 185-210.

Rorison, J. \& Voight, M. (2015). Mapping revisited: A second look at the postsecondary data domain. Institute for Higher Education Policy.

Rose, M. (2014). Academic performance, retention, and graduation comparisons: SOAR versus Non-SOAR students. San Bernardino: CSUSB Office of Institutional Research.

U.S. Census Bureau (2017). Quickfacts. Retrieved from https://www.census.gov/quickfacts/CA.

U.S. Census Bureau (2017). Quickfacts. Retrieved from https://www.census.gov/quickfacts/fact/table/sanbernardinocountycalifornia/PST120216.

U.S. Census Bureau (2017). Quickfacts. Retrieved from https://www.census.gov/quickfacts/fact/table/riversidecountycalifornia/AGE115210.

U.S. Department of Education National Center for Education Statistics Integrated Postsecondary Education Data system (IPEDS) (2017). Retrieved from https://surveys.nces.ed.gov/ipeds/VisGlossaryAll.aspx?.

Vanderburgh, W. L., Satterlund, A. M., Lopez-Wagner, M. C., Carollo, T., Wallace, Q., Oxendine, J., Taing, A.,...\& Albrecht, L. (2015). Coyote First STEP 2015 Report \#1. San Bernardino: California State University, San Bernardino, Office of Institutional Research. 